\title{
Neonatal morbidity following control of maternal diabetes with human insulin
}

\author{
Manouri P Senanayake ${ }^{1}$, M K S Gunawardene ${ }^{2}$
}

Sri Lanka Journal of Child Health, 2000; 29: 11-14

(Key words: Maternal diabetes, human insulin, neonatal morbidity)

\begin{abstract}
Objectives To assess the clinical, biochemical and echocardiographic findings of infants born to diabetic mothers given human insulin and to compare the impact of pre-gestational and gestational diabetes.

Design Prospective descriptive study.

Method Fifty one infants born to diabetic mothers treated with human insulin were studied. 23 had pregestational and 28 had gestational diabetes. Mode of delivery, prematurity, birth weight, asphyxia, plethora, congenital malformations, hypoglycaemia and hyperbilirubinaemia were analysed. The data was also compared with the details of the total birth cohort group of the same unit.
\end{abstract}

Results Caesarian section was performed in 55\%. Birth weights of over $3.5 \mathrm{~kg}$ were seen in $15.6 \%$ while prematurity was present in 10\%. Small-for-dates (14\%), large-for dates (4\%), symptomatic hypoglycaemia (2\%) asymptomatic hypoglycaemia $(12 \%)$, plethora $(2 \%)$, hyperbilirubinaemia $(12 \%)$, congenital malformations (13\%) and cardiac septal hypertrophy $(8 \%)$ were the main morbidity features. Prematurity, low birth weight and cardiomyopathy were significantly higher in pregestational diabetes. Caesarian sections, prematurity, high birth weight and congenital malformations were higher in the study group when compared to the general birth cohort.

Conclusions Morbidity in this series was higher than in the general population despite strict control of diabetes with human insulin.

\section{Introduction}

Infants born to diabetic mothers need special attention during their neonatal period due to physical characteristics, structural malformations and biochemical derangements. The morbidity pattern depends on the antenatal treatment protocols for

${ }^{1}$ Senior Lecturer in Paediatrics, Faculty of Medicine, University of Colombo ${ }^{2}$ Paediatric House Officer, De Soysa Hospital for Women, Colombo maternal diabetes and therefore varies between maternity units. Human soluble insulin, the best form of insulin recommended for obstetric use became widely available only in recent years. We undertook this study to determine the outcome of diabetic mothers given human insulin in a tertiary hospital in Sri Lanka.

\section{Objective}

To analyse the neonatal morbidity and mortality of infants born to Sri Lankan mothers treated with self injected human insulin for control of diabetes during pregnancy; and to compare the outcome of pregestational and gestational diabetes, within this cohort.

\section{Design}

A prospective descriptive study.

\section{Method}

A prospective study was carried out on all live infants born to diabetic mothers treated with human insulin in the University Obstetric Unit of the De Soysa Maternity Hospital Colombo in 1995 during a period of 12 months. Patients managed with dietary therapy alone were excluded from the study. The criteria for diagnosis of pre-gestational and gestational diabetes and the risk factors determining the timing of screening with the $75 \mathrm{~g}$ oral glucose tolerance test (OGTT) are shown in Table $1^{1}$. Laboratory constraints prevented universal screening. High risk mothers were screened at the booking visit and those with relative risks at 20 weeks of amenorrhoea. The borderline cases of "impaired glucose tolerance" defined according to the World Health Organisation criteria of a two hour blood glucose level of $120 \mathrm{mg} \%$ to $180 \mathrm{mg} \%$ were not included in this study.

Glycaemic control of the entire study population was by self injected human insulin. Informed consent was obtained and the neonates were monitored for clinical and metabolic abnormalities ${ }^{2,3.4}$. The variables analysed were mode of delivery, gestational age, birth weight, crown heel length, birth asphyxia, glucose homeostasis, hyperbilirubinaemia, respiratory distress and congenital malformations as listed in Table 2. Echocardiographic 
investigation for the presence of asymmetrical interventricular septal hypertrophy was carried out at age 3 months ${ }^{5}$. The anthropometric and neonatal morbidity patterns were compared in the pre-gestational and gestational groups and a comparison with the overall birth cohort in this unit during the given 12 month period, was made.

Table 1

Criteria for diagnosis and risk factors for screening

\section{Criteria for diagnosis}

Pre-gestational diabetes IDDM (Type 1)

Gestational diabetes

Abnormal 75g OGTT

detected during pregnancy and reverted to normal at six weeks postnatally.

Impaired Glucose $2 \mathrm{hr}$. blood glucose level Tolerance

High Risk

Risk factors

Previous baby $>3.5 \mathrm{~kg}$

Unexplained stillbirths

Polyhydramnios

Large fetus

Two first degree relatives

diabetic

Fetal anomalies associated

with diabetes

Table 2

Abnormalities associated infants of diabetic mothers

\begin{tabular}{|l|l|}
\hline Macrosomia & Congenital heart defects \\
\hline Prematurity & Cardiomyopathy \\
\hline Hypoglycaemia & Renal vein thrombosis \\
\hline Respiratory distress & Persistent fetal circulation \\
\hline Polycythaemia & Caudal regression syndrome \\
\hline Hyperbilirubinaemia & Small for dates \\
\hline
\end{tabular}

\section{Results}

A total of 51 infants were studied. They comprised of 23 born to mothers with pre-gestational diabetes and 28 to those with gestational diabetes. There were no neonatal deaths among the infants born to diabetic mothers. Caesarean section was the mode of delivery in $28(55 \%)$ of these 51 infants, in comparison to the average Caesarean rate in this unit for the same period which was $1678(25.6 \%)^{6}$. A gestational age of less than 37 weeks occurred in $5(10 \%)$. Birth weights in excess of $3.5 \mathrm{~kg}$ were found in $8(15.6 \%)$ in the study population, and in $525(8 \%)$ of the total birth cohort (Table 3$)^{7}$. Congenital malformations were seen in $13 \%$ and the heart was the organ most often affected. Malformations showed a significant increase in comparison with the total births during this period ${ }^{8}$ (Table 4). Asymmetrical septal hypertrophy persisted in 04 infants who were apparently normal at age 3 months, but data was not available for comparison in the total births. No gender related difference in morbidity was seen.

On comparison of the two groups of infants born to mothers with pre-gestational and gestational diabetes the mean birth weight was $3.03 \mathrm{~kg}$ in gestational diabetes. Morbidity was significantly higher $(\mathrm{p}<0.05)$ in the pregestational group with regard to low birth weight, prematurity and cardiomyopathy (Table 5). Polycythaemia, hyperbilirubinaemia and congenital malformations were commoner in this group although the numbers were too small for statistical analysis. No neonatal deaths were observed in this study.

Table 3

A comparison of infants of diabetic mothers with total births in the given period

\begin{tabular}{|l|l|l|}
\hline & \multicolumn{1}{|c|}{$\begin{array}{c}\text { IDM } \\
(\mathrm{n}=51)\end{array}$} & $\begin{array}{c}\text { Overall } \\
\text { Incidence } \\
(n=6536)\end{array}$ \\
\hline Prematurity & $5(10 \%)$ & $138(2.1 \%)+$ \\
\hline $\begin{array}{l}\text { Mode of Delivery } \\
\text { LSCS }\end{array}$ & $28(55 \%)$ & $1678(25.6 \%)$ \\
\hline $\begin{array}{l}\text { Birth weight } \\
<10 \text { th centile } \\
>9 \text { th centile } \\
<2.5 \mathrm{~kg}\end{array}$ & $7(13.7 \%)$ & not assessed \\
$>3.5 \mathrm{~kg}$ & $2(4 \%)$ & not assessed \\
\hline Hypoglycaemia & $6(11.7 \%)$ & $1187(18.1 \%)$ \\
\hline $\begin{array}{l}\text { Congenital } \\
\text { malformations }\end{array}$ & $7(15.6 \%)$ & $525(8 \%)$ \\
\hline
\end{tabular}

Table 4

Congenital malformations in infants of diabetic mothers

\begin{tabular}{|l|l|l|}
\hline & \multicolumn{1}{|c|}{$\begin{array}{c}\text { IDM } \\
(n=51)\end{array}$} & $\begin{array}{c}\text { Overall } \\
\text { Incidence } \\
(n=6536)\end{array}$ \\
\hline $\begin{array}{l}\text { Type of abnormality } \\
\text { Skeletal }\end{array}$ & $2(3.9 \%)$ & $7(0.1 \%)$ \\
Cardiac & $5(10 \%)$ & $19(0.2 \%)$ \\
CNS & 0 & $20(0.3 \%)$ \\
Alimentary & 0 & $7(0.1 \%)$ \\
Hypoplastic lung & 0 & $3(0.04 \%)$ \\
\hline Multiple & $1(1.9 \%)$ & $3(0.04 \%)$ \\
Malformations & & \\
\hline
\end{tabular}


Table 5

Clinical and biochemical characteristics of pre-gestational and gestational diabetes

\begin{tabular}{|l|c|c|c|}
\hline & Pre-gestational $(n=23)$ & Gestational $(n=28)$ & P value \\
\hline Prematurity (p.o.g <37 wks) & $13(13 \%)$ & $2(7 \%)$ & $<0.05$ \\
\hline Mode of delivery & & & $>0.05$ \\
Elective LSCS & $10(60.9 \%)$ & $10(50 \%)$ & \\
Emergency LSCS & 04 & 04 & $>0.05$ \\
\hline Birth weight & $03(13 \%)$ & $05(17.8 \%)$ & $<0.05$ \\
$>3.5 \mathrm{~kg}$ & $04(17.3 \%)$ & $02(7.1 \%)$ & $>0.05$ \\
$<2.5 \mathrm{~kg}$ & $05(21.7 \%)$ & $03(10.5 \%)$ & \\
\hline Hypoglycaemia & 00 & 02 & $>0.05$ \\
Symptomatic & 05 & $25(89.5 \%)$ & \\
Asymptomatic & $18(78.3 \%)$ & 00 & \\
\hline Normoglycaemia & $01(4.3 \%)$ & $02(12 \%)$ & \\
\hline Polycythaemia (PCV $>70 \%)$ & $04(17.3 \%)$ & & \\
\hline Hyperbilirubinaemia & &
\end{tabular}

\section{Discussion}

Large for dates, plethoric, moon faced, preterm infant with respiratory distress syndrome was not seen in this cohort. All infants were examined by one coauthor to avoid individual variations in clinical observations. Hypocalcaemia, hypomagnesaemia, and birth trauma were not encountered. However, this birth cohort had a five fold increase in the incidence of congenital malformations. Asymmetrical septal hypertrophy (ASH) and septal defects were the commonest cardiac abnormalities. ASH is a recognised pathology in infants of diabetic mothers with some series reporting a frequency of approximately $30 \%$. We found this self limiting cardiomyopathy in $8 \%$ of apparently normal infants, indicating the need for routine echocardiographic scanning for this abnormality.

The mode of delivery showed a significantly higher rate of elective caesarian sections as well as preterm deliveries. However, respiratory distress syndrome was not a problem we met with, despite the majority not having had prophylactic steroid therapy. Although the male gender has been implicated as a predictor of poor outcome, our study did not show a gender related morbidity pattern for any of the variables ${ }^{9}$.

The prevalence of diabetes in pregnancy cannot be ascertained from this study because it is a selected sample of only insulin treated mothers. The relatively high proportion of pre-gestational diabetes may reflect the referrals into this unit, and their special interest in managing medical disorders complicating pregnancy. Improved medical management of young diabetics may account for the increased numbers of women with diabetes getting pregnant. It is noteworthy that it was this group of pre-gestational diabetes that showed a higher morbidity with regard to both biochemical and structural abnormalities.

The gestational group had a mean birth weight above the average. Low birth weight was seen more in the pre-gestational group. The increase in low birth weight infants following pre-gestational diabetes may be due to vasculopathies associated with long standing diabetes ${ }^{10}$.

The reduced number of large for dates infants (4\%) seen in our series indicates improved glycaemic control antenatally. However, congenital malformations, prematurity, and hypoglycaemia were seen in a significant number of infants indicating that morbidity is seen despite good control of diabetes during pregnancy. Hyaline membrane disease was not a problem in our patients confirming the lower incidence of inhibition of pulmonary surfactant synthesis seen is Sri Lanka ${ }^{11}$.

In our study only $4 \%^{2}$ had birth weights above the 90th centile for gestational age. However, birth weights in excess of $3.5 \mathrm{~kg}$ showed a significant increase in comparison with the birth weights. This finding reiterates that macrosomia (i.e. a large birth weight irrespective of gestational age), should be redefined as birth weights over $3.5 \mathrm{~kg}$, for our setting, and not $4.5 \mathrm{~kg}$. We found that morbidity remained in excess of the general population despite improved metabolic control during pregnancy. 


\section{Acknowledgements}

We wish to thank Prof. H R Seneviratne and Prof. S $\mathrm{P}$ Lamabadusuriya for permitting this study on patients under their care, Dr S Narenthiran for performing the echocardiographic studies, Dr C N Wijeyeratne and medical and nursing staff of the University Obstetric and Neonatal Units of the De Soysa Maternity Hospital for Women, Colombo for their help in the management of these patients.

\section{References}

1. WHO (1985) Technical Report Series 727 diabetes Mellitus. Report of a WHO Study Group. Geneva, World Health Organisation.

2. Boo N Y. Morbidity and Mortality of infants if diabetic mothers born at the Maternity Hospital, Kuala Lampur. Medical Journal of Malaya 1992; 47(I): 56-9.

3. Faquih A M, Mir N A, Kishan J, Legnain M. Pattern of neonatal morbidity and mortality in infants of diabetic mothers. Asia Oceania Journal of Obstetric \& Gynaecology 1981; 4(2):171 -6.

4. Hoshi J, Nishida H, Takahashi N, Kabe K, Watanabe $\mathrm{Y}$ et al. Perinatal morbidity of infants of diabetic mothers. Acta Paediatric Japan 1991; 33(2):159-65.
5. Vural M, Leke L, Mahomedaly H, Maingourd Y, Kremp 0, Risbourg B. Should an echocardographic scan be done routinely for infants of diabetic mothers? Turkish Journal of Pediatrics 1995; 37(4): 351-6.

6. De Silva G D 1, De Silva M V C, Lamabadusuriya S P. An analysis of admissions and Deaths at the University Neonatal Unit, De Soysa Hospital for Women - Paper presented at the Sri Lanka Paediatric Association Annual Scientific Sessions, May 1995.

7. De Silva G D 1. Birth weight of Sri Lankan babies and methods of identifying I U G R. (personal communication)

8. De Silva G D 1. Prevalence and spectrum of congenital abnormalities in the newborn. (personal communication)

9. Bracero L A, Cassidy S, Byrne D W. Effect of gender on perinatal outcome in pregnancies complicated by diabetes Gynecol Obstet Invest 1996; 41(1):10-4.

10. Mazzone D, Milana A, Grasso S, Nicotra C, Millana G, Dell'Aquila N. The newborn infant of the diabetic mother: the clinical findings in 431 subjects, Pediat Med Chir 1993; 15(3):257-61.

11. Nogee L, McMahan M, Whitsett J A. Hyaline membrane disease and surfactant Protein, Sap-35, in diabetes in pregnancy. American Journal Perinatology 1988; 5(4): 347-77. 